Another century passed after the invention of his pulsilogy before the pulse came to be counted as we count it at the present day. Sir John Floyer, a most observing physician, also remembered for books on cold bathing and asthma, published in 1707 "The Physician's Pulse Watch." After a dedication to Queen Anne the preface gives an account of the author's invention. "I have for many years tried pulses by the minute on common watches and pendulam clocks when I was among my patients; after some time I met with the common sea minute glass, which I used for my cold bathing, and by that I made most of my experiments ; but because that was not portable I cansed a pulse-watch to be made which run sixty seconds, and placed it in a box to be more easily carried, and by this I now feel pulses." When you know that the grandfather of a member of the present staff of this hospital was born within ten years of the publication of Sir John Floyer's book you will realise how recent is the practice of counting the pulse by a second hand on a watch. I shall not trouble you with a history of the numerous instruments for registering the pulse. In "La Circulation et le Pouls" of Dr. Ozanam you will find a full discussion of spbygmographs ap to 1886 and in the latest editions of physiological manuals a continuation to the present day. Such methods are of use for graphic purposes in the laboratory, but at the bedside the finger trained to a learned touch must be our instrument and is less liable to error than any mechanical contrivance yet invented.

You have already been tanght how to feel the pulse so I will only remind you to exercise some care in finding the artery, to keep your finger upon it thronghout your observation, to exercise equal pressure, to count the pulse more than once, to compress the artery lightly first and then more firmly, and finally to make a rule of feeling the pulse in both wrists for purpose of comparison. Study your own pulse and several normal pulses and consider their character as well as their rate. I have had printed a list of eight varieties of pulse which are to be observed in the medical wards this day and which you can go and feel at any proper time.

Slow: Seaman, aged thirty-one years. Luke: 10. (28 beats in a minute.)

Fast: Girl, aged sixteen years. Faith: 2. (120 beats in a minute.) Feeble: Bov, aged ten years. Mark : 15 . Bov. aged eleven years. Mark: 14. Man, a ared forty-three years. Mark: 17

Dicrotic (at times): Man, aged forty-three years (with enteric fever). Rahere: 4 .

of unequal beat: Boy, aged fourteen years (with mitral regurgitation). Mark : 16

Of aortic regurgitation (water-hammer pulse): Man, aged nfty.four years. Matthew: 18

Artery hard: Man, aged fort reight sears (gout) Mark: 18 . Irigh tension: Man, aged fifty-two years (renal disease). Luke : 24.

The slow pulse of 28 is remarkably distinct and there do not seem to me to be any beats which do not reach the wrist as there sometimes are in such slow pulses. You may easily find many other examples of swift pulse besides the girl aged sixteen in the list. Look at the temperature charts over the beds and satisfy yourselves that a raised temperature is accompanied by a rapid pulse. Two of the feeble pulses are in boys recovering from acute illnesses, and the third is a result of long-continaing wasting disease. Make yourselves familiar with the dicrotism so frequent in the pulse of enteric fever, with the inequality of beat of the pulse of mitral regurgitation and with the peculiar shock of the pulse of aortic regurgitation. You may, I think. satisfy yourselves that the artery itself is hard in the man with gout. This is an observation in which a mistake is often made. I have many times found by dissecting it out post mortem that a hardness which seemed a property of the wall of the artery was really a result of the blood stream, the artery being free from thickening or calcification.

Take early opportunities of observing in the wards some other pulses of which there do not chance to be typical examples to-day-the pulse easily altered by slight excitement so often to be seen in exophthalmic goitre and in the people we call nervous; the pulse of unequal groups common in tuberculous meningitis ; the bounding pulse of pneumonia and that of some cases of cerebral bæmorrbage ; the pulse influenced from day to day by drugs such as digitalis. Of all these you will soon come across examples. Note the difficulty of being quite sure that the pulse has stopped when you bave been feeling it for a period of time with increasing difficulty. However marked the characteristics of the pulse may be do not hasten to a diagnosis from that observation alone. The character of the pulse will sometimes tell you whether an abdominal pair is due to the recent perforation of a gastric ulcer or to a general peritonitis. Its regularity and normal beat will tell you in a few rame cases that a cardiac murmur is produced at the pulmonary and not at the aortic valves.

The state of the pulse is an important aid to diagnosis in all cases ; it is the guide to immediate treatment in some and in many others it is one of the chief prognestic indica. tions. Dr. Ewart in his interesting and useful book, "How to Feel the Palse and What to Feel in It," mentions seventy. two terms formerly applied to as many pulses. This method of elaborate nomenclature of the pulke begins with Galeb and may be dismissed with the remark of Heberden: "Such minute distinctions of the sereral pulses, if they do not exist chiefly in the imagination, at least have little place in the knowledge and cure of diseases."9 $\mathrm{My}$ advice to you is not so much to ask what a variety of pulse which you may feel is called as what does it mean and what is its relation to the case in which you discover it. It: was a conversation on the pulse with Dr. William Ogle, a very learned physician and editor of Aristotle, which sug. gested to me the subject of this lecture. It is not intended to be exhaustive or to do more than make the beginning of the study of the pulse interesting to you. I may fitly end it with Galen's first words in his short treatise for students:

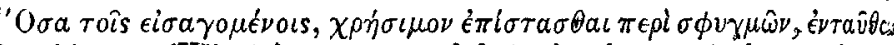
$\lambda \epsilon \chi \theta \dot{\eta} \sigma \epsilon \tau a l$ (What is most useful to beginners to know about the pulse I have set forth here).

\section{THE OUTBREAK OF ENTERIC FEVER AT CLIFTON. 1}

By D. S. DAVIES, M.D. Lond., D.P.H. CANTAB, MEDICAL OFFICER OF HEALTH OF ERISTOL.

[THE epidemic of enteric fever at Clifton caused by sewage contamination of milk and already mentioned in the columns of THE LANCET forms the subject of a valuable and exhaustive report by Dr. D. S. Davies, medical officer of health of Bristol. The report, moreover, contains a charts (reproduced herewith in fac-simile) showing the occurrence of cases on the various milk rounds. In the report the infected supply is referred to as $X$ and names are for obvious reasons omitted. Dr. Davies says:]

It is a matter for congratulation that in my first report to the new Health Committee I am able to deal with a rapidly declining epidemic the exciting cause of which has been ascertained and removed. Thus during the past three: weeks the notification returns for Cliften have fallen from 100 to 60 and again to 19 . As the third week from the stoppage of the infected supply is now just completed it is reasonable to forecast that the diminution will be fully. maintained. In my report to the Sanitary Committee on Oct. 28th I explained the nature of the epidemic and showed" how the facts already ascertained, hurriedly but with minute care, pointed to a source of contamination from one particular farm. Further investigation has proved our originall conclusions to be absolutely correct and I have nothing to withdraw from my report of that date. But the accumula tion of evidence has thrown much fresh light on some points which were then obscure, and I will endeavour to explain as: shortly as possible the main channels of diffusion of the infected milk. One farm only (X) supplied infected milk, but it found its way on to three milkman's ronnds in the following manner:-

1. The milk from the infected farm $X$ was consigned for delivery to the distributor in Bristol, by whose man it was met at the Suspension Bridge and distributed direct from the churn to customers without going to any local dairy. Any milk not used on the round was returned, however, to the branch dairy and sold to casual eustomers. This supply served during the holiday month of August and up to Sept. 26th, when the schools reopened, two districts-(a) the high level district, bounded on the east by College-road and on the south by Gloucester-road, and (3) the low level district, extending from the Mall to Grenville-place, Cumberland Basin, on the south, and as far as Bellevue on the east. On the re-assembling of the schools at the end of September, however, this supply was confined to the high level district. Some of the earliest cases developing at the beginning of October showed themselves on the low level

9 Remarks on the Pulse, 1768 : 9 Remarks on the Pulse, 1768 .
1 Abstract of a paper read before the Royal Medical' and Chirurgicas
Society on Nov. 23 rd, 1897 . 


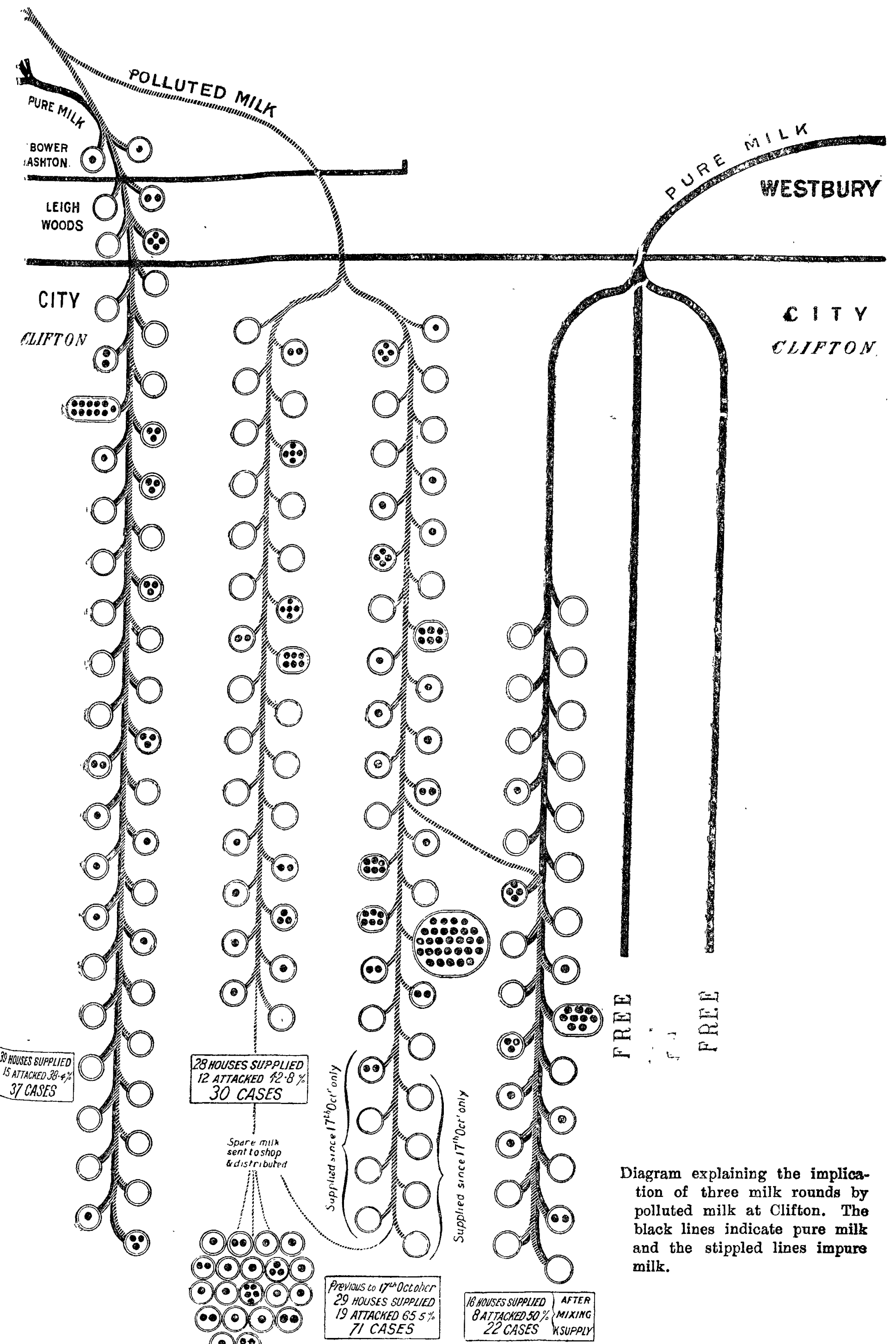


round, and many early cases also occurred on the high level round, but the incidence here was mainly in the second week of October. On the high level round 29 houses were supplied, 19 were attacked, and 71 cases resulted-a ratio of attacks to houses of 65.5 per cent. On the low level round 28 houses were supplien, 12 were attacked and 30 cases resulted-a ratio of 428 per cent. Taken together, 57 houses were supplied, 31 were attacked, and 104 cases resulted-a ratio of 548 per cent., or about two cases per house.

2. A milkman started with a pure milk-supply from Ashton, but at Bower Ashton he received a supplementary supply from $X$ (the farm alluded to in the first section) consigned to Clifton, after receiving which he supplied milk to Bower Ashton, two cases of typhoid fever resulting, then proceeding to Leigh Woods. where six more cases appeared in two houses supplied, and then entered Clifton. In the course of his Cliftion round the following resulted : 39 houses were supplied, 15 were attacked ; ratio of attacks to houses 38.4 per cent.; the total number of cases was 37 , or not quite one case per house. In this case a large quantity of good milk was polluted with a comparatively small quantity of infected milk and it will be noted that the attack rate upon houses supplied was smaller and the number of cases per house less. In one school, however, no fewer than 13 cases resulted and two were fatal. I may add that this parveyor had no right to puichase the $\mathrm{X}$ milk from the man who was forbiden to sell it. (The report then stated that very great difficulty arose in consequence of statements made to the medical officers' department which failed to give any expla. nation of the Ashton ard Leigh Woods cases. The facts were discovered by a house-to-house visitation and subsequently the whule transacri. $n$ was explained.)

3. The third and last iwplicated supply came originally from a farm at Westbury, to which no suspicion attaches, and this furnishes one of the most interesting features of the whole epidemic The method of procedure adopted in working out the epidemic is this. As soon as suspicion attaches to a farm this is inspected, lists of the customers on the various rounds are obtained, the milkmen on implicated rounds are called to give evidence, the routes of each round are mapped out, and the lists and maps compared with the fever case-books compiled from the inquiries on notified cases. The milk from the Westbury farm is brought into Bristol on three rounds. Two of these rounds were found to be entirely inrocent of cases, and the third round was (with the excep'ion of the single case of a servant in one houne, situa ed vear the dairy where the returned infecred milk went, and from which occasional supplies were possibly obtained) also quite innocent of cases up to a certain print. but beyond this point cases began to occur wi h marked frequency. These facts went a long way towards exonerating the farm itself as a source of infection. On comparing the mapped-out routes it was observed that at the very corner where this change from freedom to inftetion occured this milk round crossed that of the X supply (previously referred to), and we were prepared to receive the admis: ion that at this point, on occasions when the milkman fuund the demands of one large college house had shortent $d$ his supply, he was in the habit of buying a supplementary supply from the other who carried the infected $\mathrm{X}$ milk. Atter this cases commenced at the very next house suppl ed and recurred with considerable frequency throughout the entire route. The following are the results obtained: Before adding the infected milk 11 houses were supplied, 1 house was attacked, or 9 per cent.; 1 case resulted. After adding the infected milk 16 houses were supplied, 8 were at tack ed, or 50 per cent. : 22 cases resulted.

The explanation of this implication, which for some time seemed obscure, settles the question of causation and may silence some critics who, firiling to trace from their imperfect knowledge any posible channel of infection, have traversed my statements while they have uniformly neglected the courtesy of asking me if $I$ have any explanation. All the persons concerned have admitted before witnesses the accuracy of the facts I here adduce. In the aggregate up to Bunday, Nov. 14th, 1897, we find :-

Total houses attacked.

Houses attacked on regular rounds

Houses. Cases.

Houses attacked obtaining casual supplies from the

branch to which intected milk was returned ... 20

Houses attacked oltaining milk from dairymen not known to obtaiı infected supplies (no multiple cases in any snch house)
I am thus able to account satisfactorily for 195 out of $a$ total of 208 or 93.7 per cent. of the total cases; and when it is remembered that the infected milk was supplied to one retail shop round which a cluster of cases has occorred and to one refreshment room, and when the chances of infection by visiting are taken into account, the percentage of failure, which I hope further inquiry will reduce, is very small. The number of multiple attacks in houses upon the infected supplies is very notable. The largest number in any one house (a schoolhouse) was 29 ; in others $11,9,7,6.6,6,5$ $5,5,4,4,4,3,3,3,3,3,3,3,3$ cases occurred, and several double cases in other houses. No multiple cases occurred in any house to which an infected supply cannot be traced.

[Dr. Daries here mentioned that at Clifton College, containing large numbers of boys at susceptible ages, 5 " houses" only were attacked, every one of which received, mixed or unmixed, the infected milk. Fach circumstance of the attacks was satiofactorily explained, and it became possible to advise with confidence that the work of the school should continue without interruption and without fear of further infection. Several instances of infection under special conditions were also quoted. In one case a lady attacked was the only one in the house who drank unboiled milk. In another case a child of nine years of age on a day visit to Clifton drank some of the unboiled infected mill at a restaurant and developed enteric fever at the end of a week (the incubation period in milk typhoid may be as short. as five days). The infected milk was supplied to an institrtion containing sixty-three pexsons, not one of whom was attacked, in consequence, no donbt, of the milk being invariably scalded in a steam-jacketed cylinder. Dr. Davies's report then continued:]

I have already pointed out to the Sanitary Commititee the conditions found to exist at the farm. I now lay before the committee the eity analyst's report, from which I quote: "Oct. 30th, 1897. X Farm Pump and Stream above $X$ Farm. - There is a remarkable closeness of agreement between these waters which suggests that the pump is not supplied from a spring but from the stream. Your inspection of the locality will have determined whether this is possible. The analytical results prove these samples to be bighly. charged with putrescent organic matter, whilst a direct microscopic examination, without the assistance of oulture processes, shows them to be swarming with micro-organisms. in great variety. Here also it is not possible to state with, certainty whether part of the organic filth contained in these waters is or is not of sewage origin. From a careful consideration of the data and from a knowledge of the water of the locality I think there are distinct indications of sewage pollution, but the evidence, as is generally the case with stream waters, is not conclusive. However this may be have no hesitation in saying that none of these waters are fit to be used for dairy work. I have also examined samples of milk, one received from $X$ farm on 26th inst., and one on the 28th inst. Though in some respects these samples differ from average milk there is nothing in the results to justify the assumption that water has been added to either."

[The "stream above $\mathrm{X}$ farm" is Ashton Brook, which flows through Long Ashton, a village in Somersetshire, extending for a mile or more along the main road from Bristol to Weston. The brook is utilised as the main sewer of the village. Dr. Davies found that the sewage from fifty nine houses is discharged into it and that it then flows directly through $\mathrm{X}$ farm. He adds that it appears to be the obvious dnty of the rural district council to prevent the continuance of this pollution of the brook, the dangerous nature of which had been amply shown. The Health Com. mittee of the Bristol Corporation resolved to pay for the milk destroyed to prevent infection and awarded Dr. Davies and his staff a cordial vote of thanks for the steps they had taken.]

Huntinadon Coonty Hospital.-This hospital has lately been thoroughly renovated and so far enlarged as to provide forty-two beds. Mr. Keith D. Young was con. sulted by the Board of Management and his saggestions have been carried out under the direction of $\mathrm{Mr}$. $\mathrm{K}$. Borissow, architect, of Huntingdon. A new operating theatre has been built, floored with terrazzo and lined throughout with opalite. A mortuary chapel, the gift of one of the Governors is being built. The President of the hospital is the Earl of Sandwich, and the Honorary Secretary is the Archdeacon of Huntingdon. 